\title{
Toxicological Studies on a Soil Micro-Arthropod: An Indication on the Potential Threat in Soil Humus Formation
}

\author{
Balamurali R. S., Sanalkumar M. G.*, Nandakumar S.*, Aswathy R. \\ Department of Zoology, Mahatma Gandhi College, Thiruvananthapuram, Kerala, India \\ Department of Zoology, NSS College, Pandalam, Kerala, India
}

\begin{abstract}
The soil dwelling organisms do a responsible function in the ecosystem by organic matter breakdown, nutrient cycling and soil structure stability. Agrochemicals have long been used in agriculture to control pests and diseases in crops and thereby increasing agricultural production. However most of them are toxic to non target species and may cause negative impacts on beneficial soil macro invertebrates. The four agrochemicals which are toxic in nature are tested for their toxicity to Phylosciajavanensis at different concentrations. The results of the experiments revealed that all the agrochemicals tested viz., indofil, 2, 4-D, furudan and sevin, are highly toxic to the test animal even at low concentrations. The values LC-50 and LC-100 values obtained in the present study underlined the toxicity of these chemicals to soil organisms like Phyloscia. Also the residual remains of these agrochemicals in the soil pose a threat to the habitat of soil isopods.
\end{abstract}

Keywords: Phyloscia, soil isopod, agrochemical, toxicity, LC-50

\section{Introduction}

Isopods group of organisms play a dominant role to increase soil fertility. Indiscriminate use of pesticides,herbicide and fungicide in virtue of agricultural purposes has deleterious effects on the biology of soil arthropods. The chemical treatments that eliminate the group of microorganism undoubtedly create a partial biological vacuum in soil. Many pesticides, fungicide and herbicides can kill more than just their intended targets, namely necessary microorganism in the soil. Once in the soil, they can kill the microorganism living in the soil that breaks down organic material and aid in plant growth. It can take years before microorganism can once again live in soil that has had toxic chemicals applied to it.

Pesticides are the worst enemy of many of the soil organisms on this planet. Pesticides widely affect the life of aquatic fauna which are manifested as change in physiology, biochemistry and activity levels of many enzymes. In isopods, digestive gland epithelial thickness is related to contaminated food (Odendaal and Reinecke, 2004). Drobneet.al, (2008) confirmed the occurrence of epithelial thinning as a result of stress and that reduced feeding rate coincides with reduced epithelial thickness. The action of pesticide may bring external or internal damage to many parts of the organism.

Only recently a few studies on toxicity to soil invertebrates were published, including earthworms, springtails and enchytraeids (Wislockiet.al,. 1989; Sun et.al,. 2005; Jensen et.al,. 2007; Kolaret.al,. 2008). However, its effects on terrestrial isopods are not well known (Kolaret.al, 2008). Terrestrial isopods are abundant in different ecosystems and habitats, and have an important ecological role as macro decomposers. These animals have been recognized as useful for the characterisation of chemical toxicity (Hornunget.al,. 1998; Walker et.al,. 2001), because they are easy to sample, handle and culture, and large enough to perform a variety of sub-organism studies. A multi-level approach in toxicity testing with terrestrial isopods has previously been successfully used to identify the hazard of different pesticides and nanomaterials (Staneket.al,. 2006; Drobneet.al,. 2009).Due to their important ecological role as decomposers of organic material, terrestrial isopods are widely accepted as test organisms in terrestrial ecotoxicology and ecophysiology (Lapanjeet al., 2007).

Pesticide can serve farmers money by preventing crop losses to insect and other pests. Pesticide can be classified by target organism, chemical structure, and physical state. Pesticide can also be classified as inorganic, synthetic, and biological.Like modern insecticides, herbicides were first applied on a large scale basis shortly after world war -II. Generally herbicide falls into two groups depending upon their mode of action which include Mounron and Simazin, interfere with photosynthesis and thus cause the plant to die from lack of energy. The second group is typed by the commonly used 2, 4-D (2, 4-Dicholoro phenoxy acetic acid).

A preliminary survey in the study area revealed that agrochemicals of common use in the study area are 2,4-D, indofil, carbofuran and sevin. The study assess the toxicity of commonly used agrochemicals, 2, 4 D, carbofuran, indofil and sevin on soil isopod, Phylosciajavanensis (Rich).

\section{Materials and Methods}

\section{Collection and rearing of mother culture}

Phylosciajavanensis (Rich) were collected from the study area. They were transferred to large culture chambers of which plaster of paris and activated animal charcoal in the ratio 5:2 as base. They were acclimatized in the laboratory condition for about 20 days prior to experiment. Decayed leaf bits soaked in water were given as food. 


\section{International Journal of Science and Research (IJSR) \\ ISSN (Online): 2319-7064}

Index Copernicus Value (2013): 6.14 | Impact Factor (2014): 5.611

2. Collection and rearing for subculture

(a) Preparation of subculture medium

Large plastic containers were used as culture bottles; sterile plastic bottles were kept in oven for 24 hours at $40^{\circ} \mathrm{C}$ to desterilize the bottle. Plaster of Paris and activated animal charcoal in the ratio 5:2 mixed in distilled water were kept in this chambers for setting (Plate 2.a.) This was used as a base and these bottles were fixed with water for through setting for a period of 24 hours.

\section{(b) Collection from soil and extraction}

Soil samples were collected from different locations of Chengannurthalukof Alleppey district, Kerala and the work was carried out during December, 2014. The soil samples were loaded to series of Berlese funnel for the extraction of organisms. $40 \mathrm{~W}$ bulbs were illuminated above each funnel for a period of 24 hours to extract the micro arthropod of the soil into a beaker containing thin layer of water. The collected livePhyloscia were transferred to culture bottle to acclimatise in the laboratory condition. Cleaned decayed leaves and wood pieces were given to them as food.

\section{Preparation of Stock Solution of Agrochemicals}

$1000 \mathrm{ppm}$ stock solution of Indofil (Mancozeb), 2,4-D (Hedonal), Furdan (Carbofuran) and Sevin (Carbaryl) was prepared by dissolving required quantity of chemicals in one litre of distilled water(APHA, 2005). From this stock solution different concentration of fungicide and herbicide were prepared for bioassay.

\section{Bioassay}

Various concentration like 1,3,5,7,9 and 11 ppm Indofil, 2,4 D, Carbofuran and Sevin were prepared from stock solution. A group of 150 mature isopods in three replicates and a control were tested for each concentration of these agro chemicals. Leaves were dosed with pesticide as described by Staneket.al,. (2006). The food (Decaying leaves) was soaked in respective concentration of pesticides for a period of 24 hours and was given to experimental animals and leaves soaked in distilled water was given to control animals. The mortality was recorded at 24,48,72\& 96 hours interval and the percentage mortality at different hours were calculated.

\section{Toxicity Analysis}

From the data of bioassay, lethal concentration -100 (LC100) lethal concentration - 50 (LC-50) and safe level concentration were calculated. LC-50 values was calculated by probit analysis (Finney, 1980) safe concentration were determined by the method suggested by Hart et. al., (1945).

\section{Determination of Lethal Concentrations:LC-100, LC-} 50 and Safe Level

Lethal concentration-100 (LC-100) Lethal Concentration-50 (LC-50) was calculated usingprobit analysis by Finney. Sublethal concentration was calculated following the method described by Loomis and Sternberg, 1968. One third (1/3) of the lethal concentration -50 was taken as sub lethal concentration.

\section{Results}

\section{Mortality}

\section{(a) With 2, 4-D}

Percentage mortality of Phylosciajavenensis at different hours 2, 4-D is given in table 1 . The rise in mortality was gradual as the concentration of the pesticide increases. 30, $40,40,50,60$, and $80 \%$ mortality was recorded for $1,3,5,7$, 9 , and $11 \mathrm{ppm}$ concentration of 2, 4-D respectively at 48 hours. $30,40,40,70,80$, and $80 \%$ mortality was recorded for $1,3,5,7,9$ and $11 \mathrm{ppm}$ concentration of 2, 4-D at 72 hours. 40, 50, 60, 70, 80, and 90\% mortality was recorded for $1,3,5,7,9$, and $11 \mathrm{ppm}$ concentration of 2, 4-D at 96 hours.

Table 1: Percentage Mortality of PhylosciaExposed To Different Concentration of 2, 4-D

\begin{tabular}{|c|c|c|c|c|}
\hline \multirow{2}{*}{$\begin{array}{c}\text { Concentration } \\
(\mathrm{ppm})\end{array}$} & \multicolumn{3}{|c|}{ Mortality (\%) } & $\begin{array}{c}\text { Control Mortality } \\
\%\end{array}$ \\
\cline { 2 - 4 } & 48 hours & 72 hours & 96 hours & \\
\hline 1 & 30.21 & 30.31 & 40.28 & 0 \\
\hline 3 & 40.33 & 40.31 & 50.21 & 0 \\
\hline 5 & 40.34 & 40.30 & 60.21 & 0 \\
\hline 7 & 50.21 & 70.21 & 70.21 & 5 \\
\hline 9 & 60.21 & 80.11 & 80.01 & 0 \\
\hline 11 & 80.81 & 80.32 & 90.02 & 0 \\
\hline
\end{tabular}

\section{(b)With Indofil}

Here also there was a gradual rise in the mortality as the fungicide concentration increases $50 \%$ mortality was observed for $1 \mathrm{ppm}$ concentration of fungicide at 48 hours. Cent percent mortality was observed for $11 \mathrm{ppm}$ indofil at 96 hours. 80, 90, and $100 \%$ was the mortality rate when Phyloscia were exposed to $11 \mathrm{ppm}$ fungicide at 48 hours, 72 and 96 hours respectively (Table 2).

Table 2: Percentage Mortality of PhylosciaExposed to Different Concentration of Indofil

\begin{tabular}{|c|c|c|c|c|}
\hline $\begin{array}{c}\text { Concentration } \\
(\mathrm{ppm})\end{array}$ & \multicolumn{3}{|c|}{ Mortality (\%) } & $\begin{array}{c}\text { Control } \\
\text { Mortality (\%) }\end{array}$ \\
\cline { 2 - 4 } & 48 Hours & 72 Hours & 96 Hours & 0 \\
\hline 1 & 50.01 & 50.01 & 50.21 & 0 \\
\hline 3 & 60.08 & 60.02 & 60.22 & 0 \\
\hline 5 & 60.21 & 60.01 & 70.34 & 0 \\
\hline 7 & 70.31 & 70.88 & 70.28 & 0 \\
\hline 9 & 70.21 & 80.31 & 80.28 & 0 \\
\hline 11 & 80.01 & 90.30 & 100 & \\
\hline
\end{tabular}

\section{(c) With Carbofuran}

The rise in mortality was gradual as the concentration of the pesticide increases. 10,20,30,40,and $60 \%$ mortality was recorded for 1,3,5,7,9 and $11 \mathrm{ppm}$ concentrations of furadan ( carbofuran) respectively at 48 hours. $20,30,40,50$ and $80 \%$ mortality was recorded for $1,3,5,7,9$ and $11 \mathrm{ppm}$ concentrations of carbofuran at 72 hours 50,60,70 and $90 \%$ mortality was recorded for $1,3,5,7,9$ and $11 \mathrm{ppm}$ concentrations of carbofuran at 96 hours (Table 3 ) 


\section{International Journal of Science and Research (IJSR) \\ ISSN (Online): 2319-7064 \\ Index Copernicus Value (2013): 6.14 | Impact Factor (2014): 5.611}

Table 3: Percentage Mortality of Phyloscia Exposed to Different Concentration of Carbofuran

\begin{tabular}{|c|c|c|c|c|}
\hline \multirow{2}{*}{$\begin{array}{c}\text { Concentration } \\
(\text { ppm })\end{array}$} & \multicolumn{3}{|c|}{ Mortality (\%) } & Control \\
\cline { 2 - 4 } & 48 Hours & 2 Hours & 96 Hours & $\begin{array}{c}\text { Molity } \\
(\%)\end{array}$ \\
\hline 1 & 10.21 & 20.22 & 50.31 & 0 \\
\hline 3 & 20.23 & 30.31 & 50.21 & 0 \\
\hline 5 & 30.21 & 40.21 & 50.08 & 0 \\
\hline 7 & 30.31 & 50.21 & 60.01 & 0 \\
\hline 9 & 40.33 & 50.33 & 70.03 & 0 \\
\hline 11 & 60.21 & 80.31 & 90.04 & 0 \\
\hline
\end{tabular}

\section{(d) With Sevin}

Here also there was a gradual rise in mortality as the pesticide concentration increases. 10,30,40,50 and $100 \%$ mortality was recorded for $1,3,5,7,9$, and $11 \mathrm{ppm}$ concentrations of seven respectively at 48 hour. 30, 40, 50, 70 , and $100 \%$ mortality was recorded for $1,3,5,7,9$ and 11 ppm concentrations of sevin at 72 hour. 50, 60, 70, $100 \%$ mortality was recorded for $1,3,5,7,9$ and $11 \mathrm{ppm}$ concentrations of sevin at 96 hour (Table 4.)

Table 4: Percentage Mortality of PhylosciaExposed to Different Concentration of Sevin

\begin{tabular}{|c|c|c|c|c|}
\hline \multirow{2}{*}{$\begin{array}{c}\text { Concentration } \\
(\mathrm{ppm})\end{array}$} & \multicolumn{3}{|c|}{ Mortality (\%) } & $\begin{array}{c}\text { Control } \\
\text { Mortality } \\
(\%)\end{array}$ \\
\cline { 2 - 5 } & 48 Hours & 72 Hours & 96 Hours & 0 \\
\hline 1 & 10.00 & 30.33 & 50.09 & 0 \\
\hline 3 & 30.01 & 40.34 & 60.03 & 0 \\
\hline 5 & 30.08 & 50.33 & 60.07 & 0 \\
\hline 7 & 40.21 & 50.01 & 70.01 & 0 \\
\hline 9 & 50.23 & 70.08 & 100 & 0 \\
\hline 11 & 100 & 100 & 100 & \\
\hline
\end{tabular}

2. Lethal concentration 100 (LC-100) and lethal concentration 50 (LC-50)

(a) 2, 4-D.

Lethal concentration 100 of 2, 4-D was found to be 16.000 ppm (48 hours) and 10.7041 ppm (72 hours), 13.000 ppm (96 hours). The LC-50 values were calculated to be 6.000 ppm (48 hours) and $4.9391 \mathrm{ppm}$ (72 hours) and $3.000 \mathrm{ppm}$ (96 hours). The LC-100 values of 2, 4-D is quite high for Phylosciajavanensis (Table 5).

(b) Indofil.

The LC- 100 value of Indofil was 18.0925 (48 hours), 13.8922 (72 hours) and 11.9210 (96 hours). The LC-50 value was found to be 0.8175 (48 hours), 1.4322 (72 hours) and 1.471 (96 hours).

\section{(c) Carbofuran}

Lethal concentration-100 of carbofuran was found to be 20.281 ppm (48 hour) 15.5659 ppm (72 hour) and 14.0646 ppm (96 hour). The LC-50 values were calculated to be $9.831 \mathrm{ppm}$ (48 hour) $7.1259 \mathrm{ppm}$ (72 hour) and 30.5446 ppm (96 hour) respectively.

\section{(d) Sevin}

The LC 100 value of sevin was $12.228 \mathrm{ppm}$ (48 hour) $12.0835 \mathrm{ppm}$ (72 hour) and $10.3445 \mathrm{ppm}$ (96 hour). The LC-50 values were calculated to be 6.733 ppm (96 hours) respectively.

Table 5: LC 100 and LC 50 (in ppm) of different agrochemicals at different hours

\begin{tabular}{|c|c|c|c|c|c|c|}
\hline \multirow{3}{*}{ Chemicals } & \multicolumn{3}{|c|}{ LC -100 } & \multicolumn{3}{c|}{ L -50} \\
\cline { 2 - 7 } & $\begin{array}{c}48 \\
\text { Hours }\end{array}$ & 72 Hours & 96 Hours & $\begin{array}{c}48 \\
\text { Hours }\end{array}$ & $\begin{array}{c}72 \\
\text { Hours }\end{array}$ & $\begin{array}{c}96 \\
\text { Hours }\end{array}$ \\
\hline 2,4-D & 16.000 & 10.7041 & 13.000 & 6.000 & 4.9391 & 3.000 \\
\hline Indofil & 18.0925 & 13.8922 & 11.9210 & 0.8175 & 1.4322 & 1.471 \\
\hline Carbofuran & 20.281 & 15.5659 & 14.0646 & 9.831 & 7.1259 & 3.5446 \\
\hline Sevin & 12.228 & 12.0835 & 10.3445 & 6.733 & 5.0635 & 2.1995 \\
\hline
\end{tabular}

\section{Safe concentration and sublethal concentration}

The safe level concentration of 2, 4-D was found to be $0.6099 \mathrm{ppm}$ and that of indofil was found to be $1.3545 \mathrm{ppm}$. The sublethal concentration was found to be $0.3 \mathrm{ppm}$ for 2 , 4-D and $0.1471 \mathrm{ppm}$ for indofil. The concentration of 0.5587 ppm cabofuran was found to be safe for Phylosciajavanensis (safe concentration). The concentration of $0.35446 \mathrm{ppm}$ furadan was found to be sub-lethal to this animal. Similarly $0.3732 \mathrm{ppm}$ sevin is the safe concentration and $0.21995 \mathrm{ppm}$ sevin is the sub lethal level for Phylosciajavanensis(Table 6, Figure 6).

Table 6: Safe concentration and sublethal concentration of agrochemicals tested

\begin{tabular}{|c|c|c|}
\hline Chemicals & $\begin{array}{c}\text { Sublethal Concentration } \\
(\text { ppm })\end{array}$ & $\begin{array}{c}\text { Safe Concentration } \\
(\text { ppm })\end{array}$ \\
\hline 2,4-D & 0.3 & 0.6099 \\
\hline Indofil & 0.1471 & 1.3540 \\
\hline Carbofuran & 0.35446 & 0.5587 \\
\hline Sevin & 0.21995 & 0.3732 \\
\hline
\end{tabular}


International Journal of Science and Research (IJSR)

ISSN (Online): 2319-7064

Index Copernicus Value (2013): 6.14 | Impact Factor (2014): 5.611

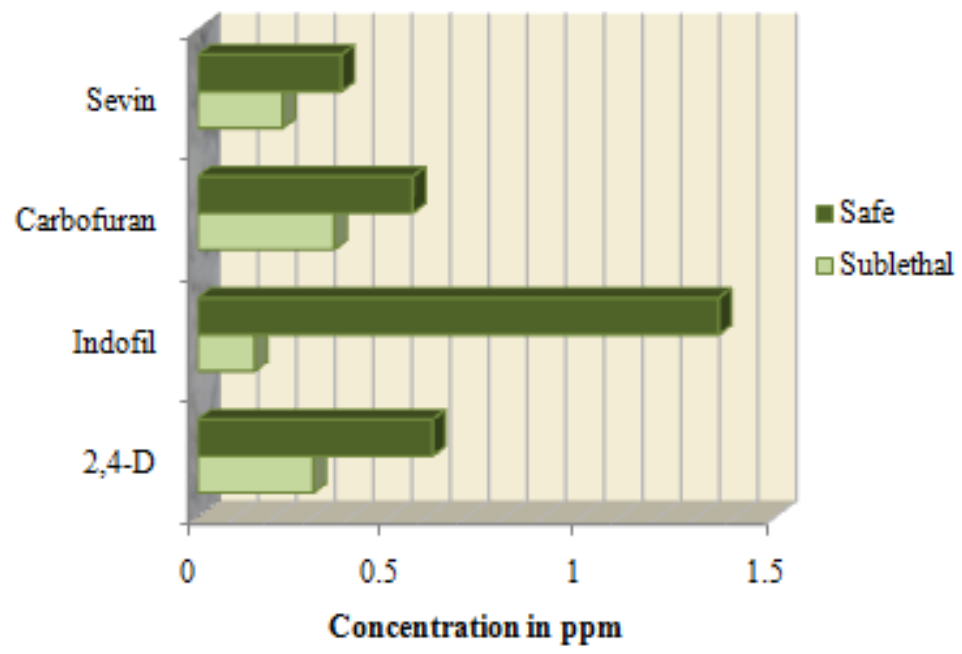

Figure 6: Safe concentration and sublethal concentration of agrochemicals tested

\section{Discussion}

Indiscriminate use of insecticides, pesticides and other toxic agrochemicals has led to the contamination of soil as well as water resources and subsequent loss of population of many useful terrestrial and aquatic organisms. There are reports of reduction in number of earthworms, collembolans, mites and other organisms in soil consequent to the regular application of these toxic agrochemicals (Andrew and Sanil, 1991; Pall and Chatterjee, 1986). Another important consequence of the use of agrochemicals is the bioaccumulation of these toxins by the soil invertebrates (Sun et.al,2005; Diaoet.al, 2007) and thereby affecting their physiology (Drobneet.al, 2008).

The percentage mortality of Phyloscia rises with the increasing concentration of all the agrochemicals tested and with increasing time of exposure. $11 \mathrm{ppm}$ concentration at 96 hour of all these pesticides tested showed 90-100 percent mortality of the organism. But at low concentrations of 1-3 ppm and the same exposure time of 96 hour, the mortality is 40-60 percent only. This means that these agrochemicals and its residual remains in the habitat of Phylosciahave a long term impact in the sustenance of the species.

The LC-50 value of furudan (3.5446) is the highest as compared with other agrochemicals tested followed by $2,4-$ D (3.000), sevin (2.1995) and indofil (11.921) at 96 hours. Also the LC-100 values showed a similar trend being the highest is furudan (14.0646) followed by 2,4-D (13.000), indofil (11.921) and sevin (10.3445). The results showed that furudan is highly toxic to Phyloscia even at low concentration and sevin is the least toxic out of the tested agrochemicals. The probit analysis results revealed that indofil is safe even upto $1.354 \mathrm{ppm}$ but the other chemicals tested are safe at less than $0.6 \mathrm{ppm}$ only.

The present study of the toxicity of different commonly used agrochemicals on soil isopod Phylosciajavanensis is in conformity with the earlier research works in this field. The isopod seems to be highly prone to the action of the agrochemicals studied and indiscriminate use of these pesticides will drastically decrease the population density and diversity of soil isopods and thereby reduces the soil fertility.

\section{References}

[1] Andrews, M.I. and Sanal, G. (1991) Toxic effects of pesticide on tadpoles of frog, RanahexadactylaLesson.,J. Ecotoxicol.Environment.,1(2):142-147

[2] APHA (2005) Standard Methods for the Examination of Water and Wastewater, American Public Health Association, NewYork

[3] Diao, X., Jensen, J. and Hansen, A.D.(2007) Toxicity of the anthelmintic abamectin to four species of soil invertebrates.Environ. Pollut.,148: 514-519

[4] Drobne, D., Jemec, A., PipanTkalec Z. (2009) In vivo screening to determine hazards of nanoparticles: Nanosized $\mathrm{TiO}_{2}$. Environmental Pollution, 157: 11571164

[5] Drobne, D., Mateja, B., Cornelis, A.M.V., Vladka, L.,Primoz, Z., Anita, J. and Polonca, T. (2008) Toxicity of imidacloprid to the terrestrial isopod Porcellioscaber (Isopoda, Crustacea), Chemosphere, 71: $1326-1334$

[6] Finney, D.J. (1980)Statistics for Biologist. Chapman and Hall, London

[7] Hart, W. P., Patrik, R. and Strong, E.R. (1945) Bioassay method for the evaluation of acute toxicity of industrial wastes to fish.Sewage and industrial wastes, 23:1380-1397

[8] Hornung, E., Farkas, S., Fischer, E. (1998) Tests on the isopod Porcellioscaber. In: Løkke H, Van Gestel CAM. (Eds). Handbook of Soil Invertebrate Toxicity Tests.John Wiley \& Sons, Chichester: 207-226

[9] Jensen, J., Diao, X. and Scott-Fordsmand, J.J. (2007) Sub-lethal toxicity of the antiparasiticabamectin on earthworms and the application of neutral red retention time as a biomarker.Chemosphere.,68: 744-750

[10] Kolar, L., KozuhErzen, N., Hogerwerf, L. and van Gestel(2008) Toxicity of abamectin and doramectin to soil invertebrates. Environ. Pollut., 151: 182-189

[11] Lapanje, A., Rupnik, M. and Drobne, D.(2007) Gut bacterial community structure (Porcellioscaber, Isopoda, Crustacea) as a measure of community level response to long-term and short-term metal pollution. Environ. Toxicol. Chem.,26: 755-763.

[12] Loomis, L., and Sternberg, S. (1968)Advanced Calculus. Addison-Wesley Publishing, London

\section{Volume 5 Issue 1, January 2016}




\section{International Journal of Science and Research (IJSR) \\ ISSN (Online): 2319-7064}

Index Copernicus Value (2013): 6.14 | Impact Factor (2014): 5.611

[13] Odendaal, J.P., Reinecke, A.J. (2004) Effect of metal mixtures ( $\mathrm{Cd}$ and $\mathrm{Zn}$ ) on body weight in terrestrial isopods. Archives of Environmental Contamination and Toxicology. 46: 377-384

[14] Pall, A. and Chatterjee, C.(1986) Effect of fungicide on the fungal biomass and soil micro-arthropod population in an undisturbed grassland of Burdwan. W.Bengal India Bur. Univ. Sci. 3:26-30

[15] Stanek, K., Drobne, D., and Trebse, P. (2006) Linkage of biomarkers along levels of biological complexity in juvenile and adult diazinon fed terrestrial isopod (Porcellioscaber, Isopoda, Crustacea). Chemosphere.64:1745-1752

[16] Walker, C.H., Hopkin, S.P., Sibly, R.M. and Peakall, D.B.(2001)Principles of Ecotoxicology. Taylor and Francis, London

[17] Wislocki, P.G., Grosso, L.S., Dybas, R.A.(1989) Environmental aspects of abamectin: Use in crop protection. In: Campbell WC (ed.) Ivermectin and abamectin, 1st edn. Springer, New York, pp 182-200 